"to comb," the instrument kombILO, "comb," is derived, while to the similar verb brosi, "to brush," belongs the noun broso, "brush," as the instrument. IrADO from iri, to walk, means "continued walking," while fos $A D O$ from fosi, "to dig," means "digging," without any idea of continuation or duration.

The philologic absurdities of Esperanto have been incontestably demonstrated by Dr. J. Couturat in his excellent study, "Etude sur la Derivation -en Esperanto." The reader is referred to this work for other innumerable examples.

4. The vocabulary of Esperanto is lacking in internationality. The most frequently occurring words are entirely arbitrary and render the language unintelligible without previous study even to expert linguists, who read and understand other artificial languages almost at sight.

5. Esperanto is extremely poor in root words. This has led to the adoption of many idiotisms and of absurd compounds, as the verb el-paroli, which ought to mean "to speak out," but is used for "to pronounce."

6. Owing to the introduction of the accusative case with extremely frequent application, and to the declension of the adjective, which is changeable according to case and number, Esperanto is too difficult for persons of average education and especially of English nationality. Most Esperantists of this country, after having devoted several years to the study of Esperanto, are unable to write a few lines correctly or to speak the language.

That Esperanto is not fit for an international language has been proclaimed by the Committee of the Delegation for the Adeption of an International Auxiliary Language. This committee, composed of great scholars of international renown, convened at Paris in October, 1907, and rejected all artificial languages, Esperanto in its present form included. It adopted, however, a system presented by Marquis L. de Beaufront, the greatest authority on Esperanto, its inventor not excluded. This system, subsequently perfected and enlarged by the Constant Committee of the Delegation, is now known chiefly as Ilo, which means "international language" by its initial letters. Ilo is as much superior to Esperanto as the latter is to the defunct Volapiik. It is not simplified Esperanto, for it has in common with the latter only a part of the conjugation, the ending of noun, adjective and adverb, and a few affixes. Everything else in Ilo is common to almost all modern artificial languages.

The New York Esperanto Society, the pioneer society in this country devoted to an international language. at its meeting of October, 1908, adopted Ilo, and at the November meeting the resolution was passed unanimously to assume the title "New York Ilo Society."

Evidently Esperanto is already undergoing the same fate as Volapük. But the Esperantists spread all kinds of false reports about Esperanto's "wonderful" growth. One "fidelulo" - speaks of 55 Esperanto journals, not mentioning those that have long disappeared, as the Medicina Revuo, etc. Another relates that "Esperanto is taught in the public schools of many lands." Fortunately for their pupils, it is merely a dream. Two thousand people in the United States are said to be speaking Esperanto fluently and correctly. A dozen would have been an exaggeration, and these have adopted Ilo, etc. But even if all these reports were true, they would not prove anything, for Volapüs could really show such successes, and yet it died because of intrinsic defects. Esperanto is following it into oblivion for similar reasons.

DR. Max TaImex.

Founder and first president of the New York Esperanto Socicty, now New York Ilo Society.

\section{Dangers in Food Adulterations}

Philadelphia, Dec. 31, 1908. To the Editor:-Food Inspection Decision 101, of the United States Department of Agriculture, states that "The department has not charged the position outlined in Food Inspection Decision 89. Pending the determination by the referee board of the wholesomeness or unwholesomeness of benzoate of soda, its use will be allowed under the following restrictions: Benzoate of soda, in quantities not exceeding 0.1 per cent., may be adiled to those foods in which generally heretofore it has been used. The addition of benzoate of soda shall be plainly stated on the label of each package of such food."

Food Inspection Decision 102 of the same department, signed by three cabinet officers, Messrs. Cortelyou, Secretary of the Treasury; Wilson, Secretary of Agriculture; and Strauss, Secretary of Commerce and Labor, states that "until further notice, vegetables greened with copper salts, but which do not contain an excessive amount of copper, and which are otherwise suitable for food, will be allowed entry into the United States, if the label bears the statement that sulphate of coppcr or other copper salts have been used to color the vegetables. Food Inspection Decision 92 is amended accordingly."

These decisions, as every practising physician must know, are fraught with great danger to the public health. There is considerable difference between the effects of any poison or irritant given in a few experiments in the laboratory, and those of the same poison taken continuously over long periods, even in small quantities.

I have not the slightest doubt that sodium benzoate (and especially the commercial of synthetic sodium benzoate) taken in foods more or less continuously, will derange digestion and set up irritative and degenerative changes in the gastroenteric mucosa. Similarly, I have no doubt that copper salts will cause chronic nephritis and it is possible that pathologic changes in the blood and in the nerves may also be originated in this manner.

If the medical profession is to make its voice heard in defense of the public health, and if the Food and Drugs Act is not to be nullified by "interpretation," it is high time that a flood of indignant protests from medical men throughout the United States shall sweep in on the secretaries of the Treasury, of Agriculture, and of Labor and Commerce.

S. Solis Cohen.

[Comment: We heartily endorse the appeal of Dr. Cohen to the medical profession to protest against these decisions, which, we understand, were adopted against the protest of Dr. Wiley.-ED.]

\section{Graduate Work in the Elementary Branches}

To the Editor:-In common with thousands of other mid. dle-aged practitioners, I have often felt the need and lack of up-to-date knowledge in the primary branches of medicine, viz.: chemistry, physiologic chemistry, histology, pathology, and bacteriology. Like others, I read and continue to buy the latest editions of books on practice, surgery, obstetrics, gynecology, dermatology, etc. We read and partially digest these works until we are satiated with fact and theory, ani difference of opinion. But we are conscious all the time that our ground work in the fundamental principles of medicine is sadly deficient as we received it twenty or thirty years ago. Most of us are so situated that we can not take the time for a year's work at school as it would necessitate giving up practice for that length of time, which means a loss of a good portion of it.

Now, with the proper text-books, a good microscope, and a small home-fitted-up laboratory, it would be possible for physicians, in leisure moments, to dig out much information, and especially when two or three could work together and could enlist the cooperation of some younger colleagues. I believe that this work would be very interesting and profit. able, much more so than going over and over the same old things in the so-called higher branches.

The first and most formidable objection is that nearly all the text-books used are too complicated and difficult for the class of men under consideration. If there were a series of books more elementary than those advertised in the medical journals, or if some competent teachers would recommend a set of books which might be read before taking up the larger works, many physicians would be glad to take up these studies in their leisure time. If Tre Journal A. M. A., which gives us almost everything else linder the sun which we can utilize in practice, could help us along this line $I$ believe that the profession would be greatly benefited.

H. F. Baylard, M.D., Cullom, Ill. 